\title{
ATAQUE AO PENSAMENTO CRÍTICO E O NASCIMENTO DE UM NICHO NO MERCADO EDUCATIVO
}

\author{
THE ATTACK TO CRITICAL THINKING AND THE BIRTH OF A NICH IN \\ THE EDUCATIONAL MARKET
}

\section{ATAQUE AL PENSAMIENTO CRÍTICO Y EL NACIMIENTO DE UN NICHO EN EL MERCADO EDUCATIVO.}

\author{
Verônica Ventorini Ferreira ${ }^{1}$; Berenice Corsetti $^{2}$
}

\begin{abstract}
RESUMO
O ensaio que apresentamos é oriundo de um estudo sistemático sobre a fundamentação ética da educação a partir do Movimento Escola Sem Partido (MESP). Tratamos o assunto, neste texto, a partir do campo das políticas para educação, tomando como referência nosso tempo caracterizado pelas relações entre os setores público e privado, que conferem caráter de mercadoria a direitos básicos do cidadão. A educação, um desses direitos, há muito é permeada por parcerias que desfiguram seu caráter de pilar fundador do Estado de Direito. Ainda observamos um segundo fenômeno, o movimento das ideias pedagógicas descortinado nessas organizações que interferem diretamente na educação. Nossos estudos buscam acessar esse fenômeno observando o modo como se apresenta, estrutura e justifica o Movimento Escola Sem Partido. Em nosso ensaio propomos apresentar a instrumentalização da crítica a Paulo Freire, presente no MESP, como fundamento de sustentação para uma possível parceria público-privada, às custas da dignidade dos profissionais e das instituições de educação básica e superior brasileiras, bem como do pensamento de uma referência planetária no campo educativo e do legado oriundo das teorias críticas.
\end{abstract}

PALAVRAS-CHAVE: Educação. Ética. Paulo Freire. Escola Sem Partido.

\begin{abstract}
This essay we present comes from of a systematic study about a ethical reasoning of the education from the Movimento Escola Sem Partido (MESP). We treat the subject, on this essay, from the field of education policies, taking our time as a reference characterized by relations between the public and private sectors, that confer character of merchandise to basic rights of the citizen. Education, one of this rights, has long been permeated by partnerships which disfigure their character of the basis of the Law State. We still observe a second phenomenon, the movement of pedagogical ideas uncovered in these organizations that interfere directly in education. Our studies seek access to this phenomenon observing the mode how does it shows, structures and justifies the Movimento Escola Sem Partido. On this essay we propose to present the instrumentalization from the critic to Paulo Freire, present on MESP, as a support base for a possible partnership public-private, at the expense of dignity of professionals and institutions of basic and higher education in Brazil, as well as a thought of a planetary reference in the educational field and the legacy from critical theories.
\end{abstract}

KEYWORDS: Education. Ethics. Paulo Freire. Escola Sem Partido.

\footnotetext{
${ }^{1}$ Doutoranda e Mestra em Educação pela Universidade do Vale do Rio dos Sinos - UNISINOS. Programa de Pós-Graduação em Educação, Linha 1: educação, história e políticas.

${ }^{2}$ Universidade do Vale do Rio dos Sinos - UNISINOS. Programa de Pós-Graduação em Educação, Linha 1: educação, história e políticas.

\begin{tabular}{c|c|c|c}
\hline Rev. Ciências Humanas & Frederico Westphalen, RS & Pg. 129-144 & Maio/Agosto 2019 \\
\hline \multicolumn{2}{c}{ Recebido em: 26/04/2019 } & Aceito em: 30/04/2019 \\
\hline
\end{tabular}
}




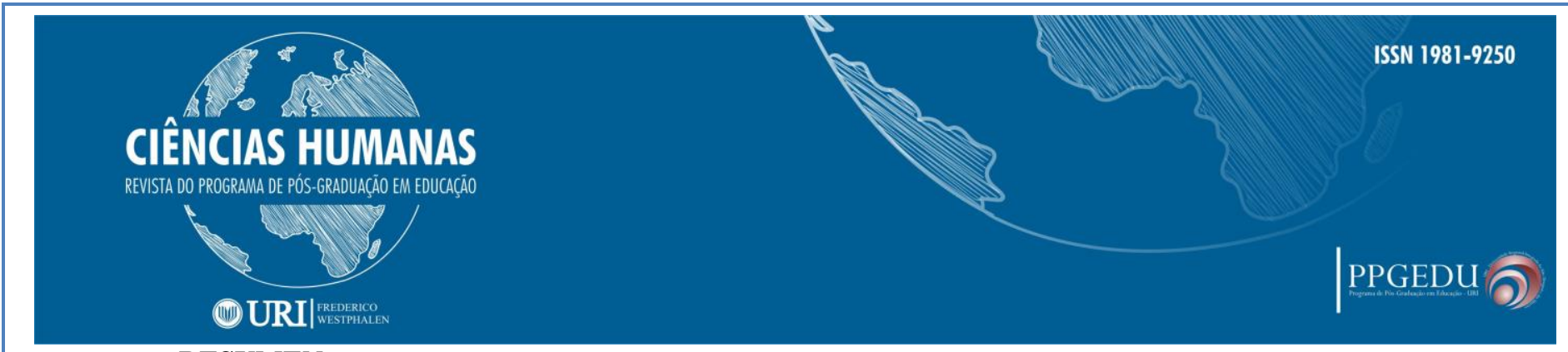

\title{
RESUMEN
}

El ensayo que presentamos es procedente de un estudio sistemático sobre la fundamentación ética de la educación a partir del Movimento Escola Sem Partido (MESP). Abordamos el asunto, en ese texto, a partir del campo de las políticas públicas para la educación, teniendo como referencia nuestro tiempo caracterizado por las relaciones entre los sectores público y privado, que confieren carácter de mercadoría a los derechos básicos de ciudadano. La educación, un de eses derechos, es permeada por las colaboraciones que desfiguran su carácter de pilar fundador del Estado de Derecho hace mucho tiempo. Aún observamos un según fenómeno, el movimiento de las ideas pedagógicas descubierto en esas organizaciones que interfieren diretamente en la educación. Nuestros estudios buscan acceder a ese fenómeno observando la manera como se presenta, se estructura y se justifica el Movimento Escola Sem Partido. En nuestro ensayo proponemos presentar la instrumentalización de la crítica a Paulo Freire, presente en el MESP, como fundamento de sustentación para una posible colaboración público-privada, a

las costas de la dignidad de los profesionales e de las instituciones de la educación básica y superior brasileñas, así como del pensamiento de uma referencia global del campo educativo y del legado derivado de las teorias críticas.

PALABRAS CLAVE: Educación. Ética. Paulo Freire. Escola Sem Partido.

\section{EDUCAÇÃO: ENTRE DIREITO E MERCADORIA}

\author{
Este mundo, que oferece o banquete a todos e fecha a porta no nariz de tantos, é ao \\ mesmo tempo igualador e desigual: igualador nas ideias e nos costumes que impõe e \\ desigual nas oportunidades que proporciona. (GALEANO, 2009 p. 25)
}

Historicamente a educação é atrelada a noção de Estado e cidadania, haja vista que, desde os primeiros contratualistas, o Estado Social é o meio de superação do Estado de Natureza, e aquele se estrutura a partir da união entre os homens, mas somente permanece e progride pela educação dos cidadãos. O que está em jogo nesse debate sobre o Estado é a liberdade humana, que se manifesta individualmente, mas que só pode vir a ser vivida em um horizonte coletivo, em que o pacto social regula as liberdades individuais, gerando o segundo nicho das liberdades, isto é, a liberdade coletiva.

\begin{abstract}
Nem a sociedade pode desconsiderar a liberdade e autonomia relativa dos indivíduos, nem o indivíduo pode se imaginar livre das fundamentais marcas nele impressas pela convivência social. Liberdade e autonomia se desenvolvem e se limitam no coletivo e é no coletivo que adquirem seu real e mais profundo sentido de cidadania. Cidadania que expressa a verdadeira realização individual e social do ser humano, adquirindo, assim, a condição de direito. (GORGEN, 2013, p. 732)
\end{abstract}

Então, cidadania é entendida como a condição do indivíduo de intervir nos assuntos públicos e privados, nos âmbitos da política e da economia. Tenhamos em vista que a economia, pertencia originariamente ao âmbito particular da vida humana, não configurava uma questão pública, significava sim estar livre de ter que prover a subsistência. 


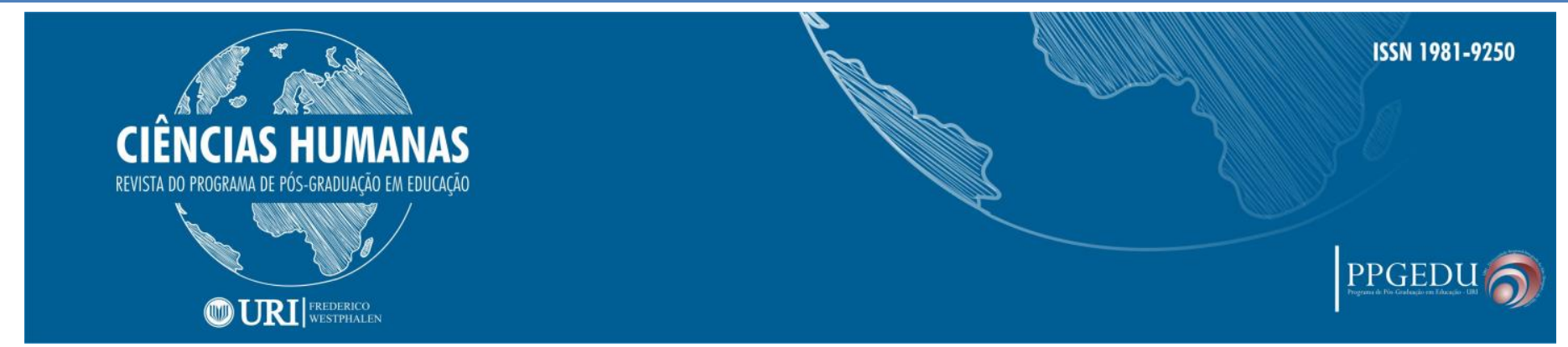

Somente no período moderno é que se transformou o "interesse privado pela propriedade privada em uma preocupação pública". (ARENDT, 2010, p.83). Assim, a economia passa a ser um assunto público, e as esferas do público e do privado, como eram conhecidas desde a antiguidade - claro que esse foi um processo longo - cedem lugar a um espaço público preocupado com demandas da vida privada.

Com a ascensão do econômico (leia-se mercado) ao posto de valor absoluto e prioritário, o Estado, acusado de dispendioso e moroso, passou a ser considerado o grande vilão do mau desempenho econômico e, na mesma lógica, do próprio desenvolvimento social. Assim sendo, o Estado deveria manter-se neutro e restrito aos setores não atraentes para o setor privado. (GORGEN, 2013, p. 735)

A cidadania precisa ser construída, é um processo formativo, e ainda que outras esferas possam contribuir, a escola em sua organização e encontro entre os humanos é o lugar em que esse processo acontece. Tanto pelo acesso e desenvolvimento do conhecimento formal, como pelo encontro entre as particularidades.

\begin{abstract}
O abalo neoliberal restringe a responsabilização do Estado pela garantia dos direitos de todos à cidadania, particularmente nas áreas de saúde e educação, não por acaso as mais onerosas e, ao mesmo tempo, as mais promissoras para a exploração econômica. Estão em jogo, de um lado, a minimalização do Estado e a degradação da educação a produto comercializável segundo as leis do mercado e, de outro, a crescente privatização do próprio Estado, posto a serviço de interesses privados. (GORGEN, 2013, p. 738)
\end{abstract}

Esse panorama inicial nos situa dentro de uma condição em que o Estado não é, como se pensa, absoluto no que toca as decisões para a sociedade, estando sob influência das corporações que fazem dos direitos dos cidadãos produtos negociáveis. Nos acomete o fato de que em matéria de parcerias, entre o setor público e privado, visando a educação, as justificativas pairam sobre um ensino de qualidade centrado em resultados. Os rankings justificam esse tipo de argumento e geram mesmo concorrência entre escolas públicas, o setor privado aparece como uma solução, em uma parceria onde o público subsidia e o privado organiza, gerando, assim, a ideia de incapacidade do público em prover educação de qualidade.

Porém, se é verdade que os resultados destas avaliações continuam a estar na base de processos indutores de concorrência, comparação e emulação nisso participando não apenas os alunos, mas, igualmente, e cada vez mais, os próprios professores e as organizações educativas, também é verdade que os efeitos de quase-mercado em

\begin{tabular}{|l|c|c|c|} 
Rev. Ciências Humanas & Frederico Westphalen, RS & Pg. 129-144 & Maio/Agosto 2019 \\
\hline
\end{tabular}

\begin{tabular}{l|l} 
Recebido em: 26/04/2019 & Aceito em: 30/04/2019
\end{tabular}




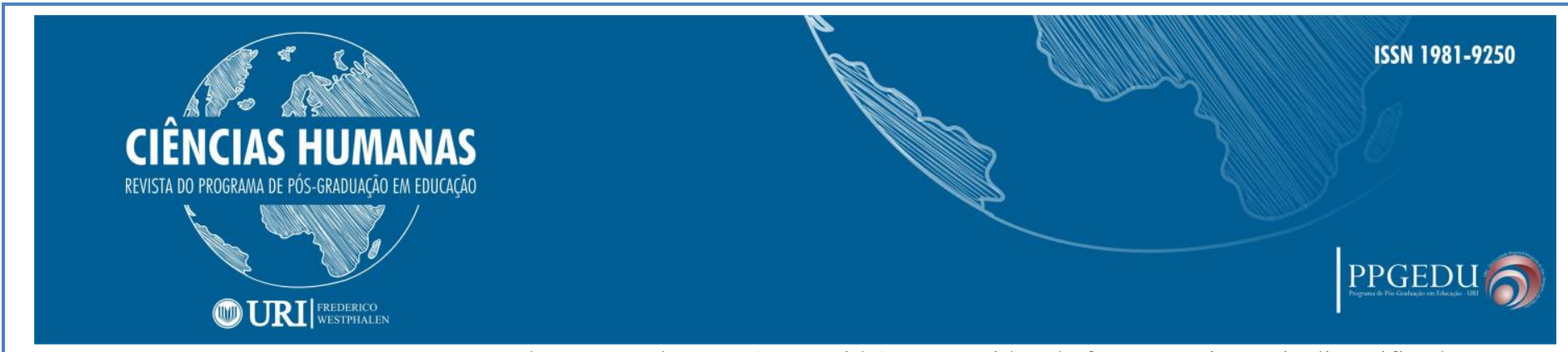

educação podem ser (e tem sido) conseguidos de formas muito mais diversificadas e subtis e, por vezes mesmo, mais eficazes do que através de rankings. (AFONSO, 2010, p.1147)

Entre as várias propostas para a educação, o contexto brasileiro conta com a Escola Sem Partido, cuja a finalidade é combater "a instrumentalização do ensino para fins políticos, ideológicos e partidários", conforme a sessão "Objetivos" no site do Movimento. Essa justificativa está situada no âmbito da moralidade civil, e aqui a promessa não é melhorar índices, mas garantir a particularidade da formação moral eleita pelos pais do alunos, de tal modo que "os conteúdos morais sejam varridos das disciplinas obrigatórias e concentradas numa única disciplina facultativa, a exemplo do que ocorre com o ensino religioso.”. Afonso, 2010 p. 1146, destaca a liberdade de escolha como um traço comum dos "fenômenos de mercado e quase-mercado em educação.", assim como passa a compor um argumento conciliador entre

[...] setores ideológicos com valores distintos, como é o caso dos neoconservadores e dos neoliberais: por um lado, da parte dos neoconservadores, a liberdade de escolha converge com o valor e centralidade da família na educação dos filhos e, portanto, com o direito de realizar escolhas que sejam compatíveis com os seus interesses. [...] (AFONSO, 2010, p. 1146)

Quando Barroso (2005, p. 76), retrata a regulação pelo mercado, aponta a relação entre o Estado e os pais dos alunos como um modelo recorrente, haja vista o fato de que os pais têm a ideia de serem consumidores - coisa comum em nosso tempo, já temos mais direitos do consumidor que do cidadão - gerando um processo de competição entre as escolas.

Quer signifique efectiva redução do poder do Estado, ou simples alteração estratégica para conservar esse poder a "aliança" entre o Estado e os pais dos alunos tem-se feito, na maior parte dos países que levaram mais longe esta "lógica de mercado", contra a influência dos professores. Como assinala McKevitt (1998) a este propósito: As reformas na Nova Zelândia e no Reino Unido basearam-se largamente na premissa de que os serviços eram dominados pelos professores e que a solução passava, necessariamente, pela redução das suas liberdadeS profissionais (p.165). (BARROSO, 2005, p.76)

Até aqui, abordando sinteticamente a estrutura das ideias que configuraram as noções de Estado, cidadão e educação, chegamos aos sistemas de regulação da educação e situamos, em um primeiro momento, a proposta do MESP como uma regulação via mercado. Entretanto, estamos desenvolvendo, em estudo que não cabe nessa proposta, a perspectiva de 


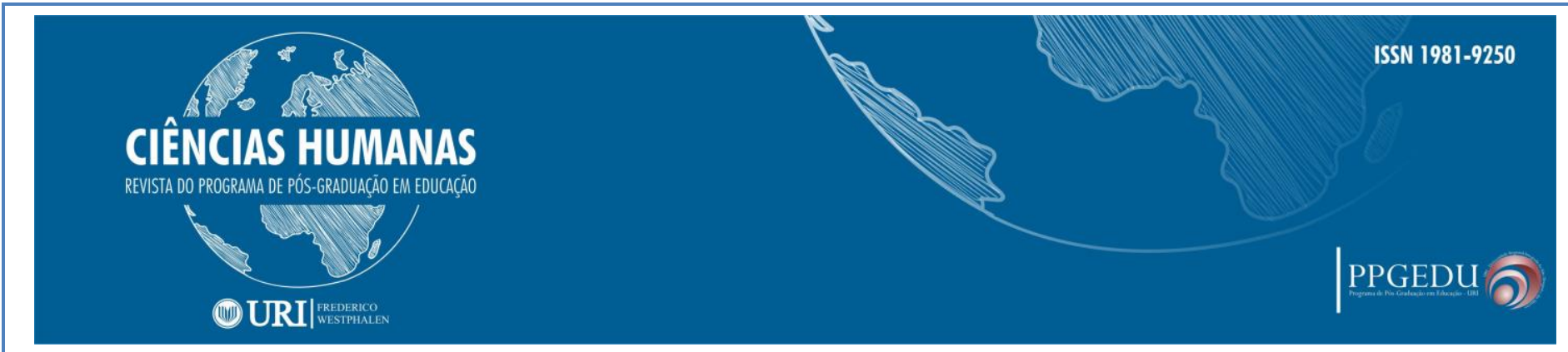

que se trata de um modo de regulação mais refinado, que incide sobre a regulação do acesso ao conhecimento pela via da prática docente. A próxima etapa consiste em abordar a relação entre verdade e ciência, para só então tocar na inserção do MESP na sociedade, tecendo, a partir daí um panorama de tomada do senso comum pela perspectiva que defendem.

\title{
ENTRE O PÚBLICO E O PRIVADO: A OPINIÃO E A VERDADE
}

Estando a ciência calcada sobre a noção da verdade, é sabido que apenas as ciências de conhecimento técnico abriram seu campo com considerável reconhecimento público, o que se deve a capacidade que possuem de reproduzir o método e, portanto, de convencimento do que apresentam. No entanto as ciências humanas se servem de outras dimensões da verdade, dimensões que implicam a historicidade e percursos racionais complexos que, apesar das tentativas, não podem ser fielmente reproduzidos em termos de método e resultado. Associamos, nossas considerações, à reflexão de Hannah Arendt sobre as verdades filosófica e fatual para compreendermos a situação da verdade no âmbito do público:

\begin{abstract}
A verdade filosófica, ao penetrar na praça pública, altera sua natureza e se torna opinião, [...] uma modificação que não é meramente de uma espécie de raciocínio para outra, mas de um modo de existência humana para outro. A verdade fatual, ao contrário, relaciona-se sempre com outras pessoas: ela diz respeito a eventos e circunstâncias nas quais muitos estão envolvidos [...] existe apenas na medida em que se fala sobre ela, mesmo quando ocorre no domínio da intimidade. É política por natureza. (AREDNT, 2009, p. 295)
\end{abstract}

Ao adentrar o campo público a verdade filosófica, enquanto experiência individual é traduzida em discurso, e se coloca ao lado dos discursos de opinião. A verdade possui um tom tirânico, é única e em si mesma, enquanto a opinião tem a capacidade de se colocar e ser alterada por outros discursos paralelos, é democrática, pois atende a mais de um indivíduo e se dá em relação com outros. Esse caráter privado da verdade a coloca fora do âmbito político, assim como toda a empresa que pretenda se alicerçar sobre alguma verdade não demonstrável pelos métodos ou pelos fatos.

Ora, temos de considerar que em nossa sociedade as universidades ocupam um papel fundamental com o que é científico e, por tanto, possuem uma relação estreita com a questão da e pela verdade. 


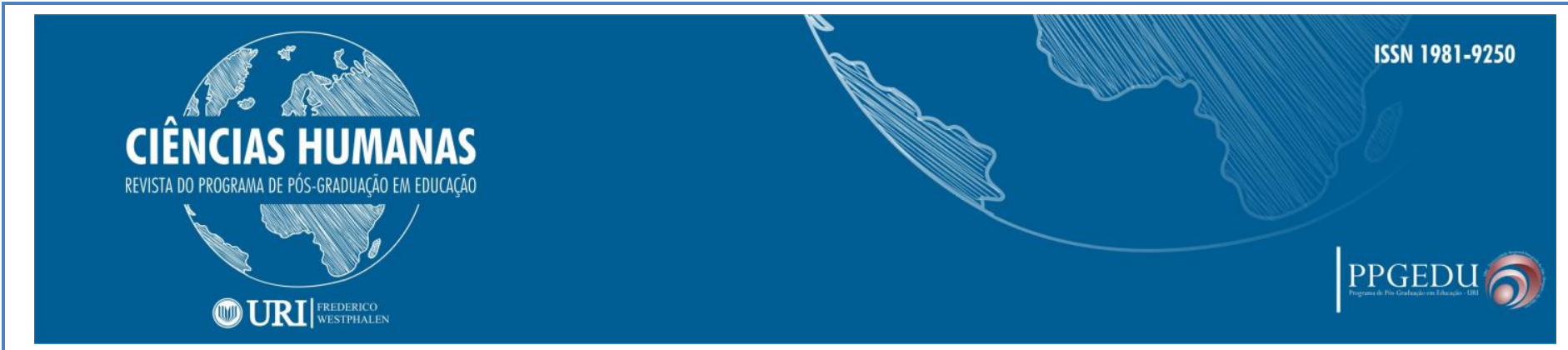

O sonho platônico, decerto, não se tornou verdadeiro: a Academia nunca veio a ser uma contra-sociedade, e em parte alguma ouvimos falar de qualquer tentativa de tomada do poder pelas universidades. Tornou-se verdadeiro, porém, aquilo que Platão jamais sonhou: o domínio político reconheceu necessitar de uma outra instituição exterior à luta pelo poder, além da imparcialidade requerida pela aplicação da justiça; não é de grande importância o fato de estarem esses locais de ensino superior em mãos privadas ou públicas, pois não só a sua integridade, como sua própria existência, dependem, seja como for, da boa vontade do governo. (ARENDT, 2009, p. 321)

Não duvidamos que as esferas social e política possam influenciar as universidades e os tribunais, o que afirmamos é que há interesses sociais e políticos, quando consideramos um governo não totalitário, de que existam instituições que possam se eximir de curvar-se ao poder político.

Gadamer ao discorrer sobre a Verdade nas ciências do espírito, na obra Verdade e Método, assim como Hannah Arendt em seu texto Verdade e Política, nos adverte do uso perverso da publicidade e da mídia para a manipulação da opinião pública. Opinião essa da qual depende nosso situar-se no mundo, pois não passamos a vida cercados por conhecimentos claros e distintos, que alcançamos em profunda reflexão, mas estamos cercados por discursos de opinião, que se propagam em redes sociais, programas televisivos e conversas rasas.

\footnotetext{
Quem não reconhece sua dependência e acredita ser livre, quando na realidade não o é, está vigiando suas próprias algemas. O próprio terror repousa no fato de que os aterrorizados aterrorizam a si mesmos. A experiência mais funesta que a humanidade fez neste século foi a de que a própria razão é corrupta. As ciências do espírito, que fazem esta experiência em si mesmas, têm assim a possibilidade especial de evitar as seduções do poder e a corrupção da sua razão. [...] Não podem desincumbir-se da responsabilidade da influência que exercem. Frente à manipulação da opinião pública pela publicidade imposta pelo mundo moderno, elas exercem, através da família e da escola, uma influência sobre o universo dos adolescentes. Onde elas se pautam pela verdade, elas imprimem um vestígio indelével de liberdade. (GADAMER, 2011, p. 55)
}

O elo entre a opinião pública e a verdade científica se dá pelo discurso, pelo uso da linguagem, logo, o que se coloca como questão é para qual finalidade se usa o discurso, se para convencer o outro sobre uma opinião ou para o compromisso com a reflexão coerente sobre o mundo. A questão pela verdade conduz ao campo ético, na medida em que esse é entendido como um relacionar-se no mundo. 


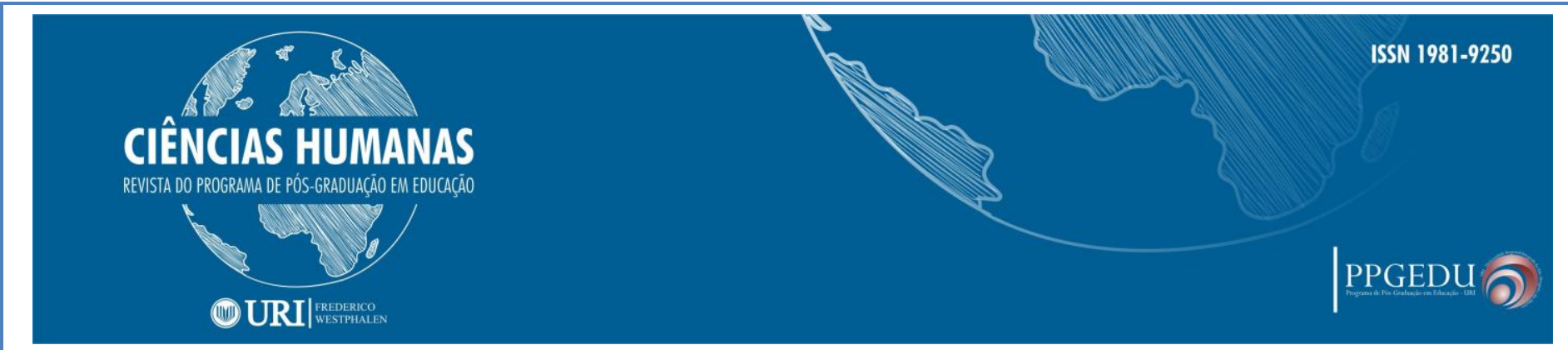

A distância entre a experiência da verdade e o discurso tem o sentido do encontrar as palavras corretas para a tradução, que nem sempre será possível como gostaríamos, no entanto, é compromisso das ciências humanas dar refúgio para esse processo de tradução, pois, como já afirmamos, a experiência da verdade é particular, traduzí-la implica sua metamorfose em coisa discursada, exteriorizada e portanto elevada ao campo público. Defender um discurso dessa natureza significa se situar no campo pré-político, saber-se participe da esfera pública enquanto intérprete das coisas do mundo, sobre as quais também se voltam a opinião pública.

Quando a questão pela verdade, não pela validade, de um discurso se coloca, recorremos a um exaustivo processo de análise, que transcende a dimensão lógica, e recai sobre a coerência da coisa que vêm à fala pela linguagem. O próximo tópico é dedicado à reflexão sobre alguns pressupostos acerca da experiência de análise, que não significa um processo metodológico rígido, mas uma preparação para o que venha a ser posteriormente a análise.

\section{PARÂMETROS PARA A COMPREENSÃO}

O fenômeno da compreensão parece se dar no fluxo de nossa existência, como se não gerasse maiores problemas. Entretanto, quando nos dispomos ao estudo de um texto, que é utilizado intencionalmente para corroborar uma ideia, o próprio fenômeno do compreender precisa ser pensado, pois a imperícia na recepção do que vem à fala nos levaria a incorrer na emissão de opiniões sobre o texto. Se o objetivo é remontar aos fundamentos de uma ideia não basta ler rasamente, é preciso estabelecer um modo de relação com o que vem à fala, isto é, recepcionar com mestria o outro que se apresenta. Para guiar essa recepção consideraremos os seguintes pontos: o problema e a pergunta; a experiência hermenêutica.

\section{O problema e a Pergunta}

Podemos afirmar que a pergunta dota de sentido a resposta, assim como o dito sempre é uma resposta. Elaborar uma pergunta de modo a permitir uma resposta é tarefa pouco 


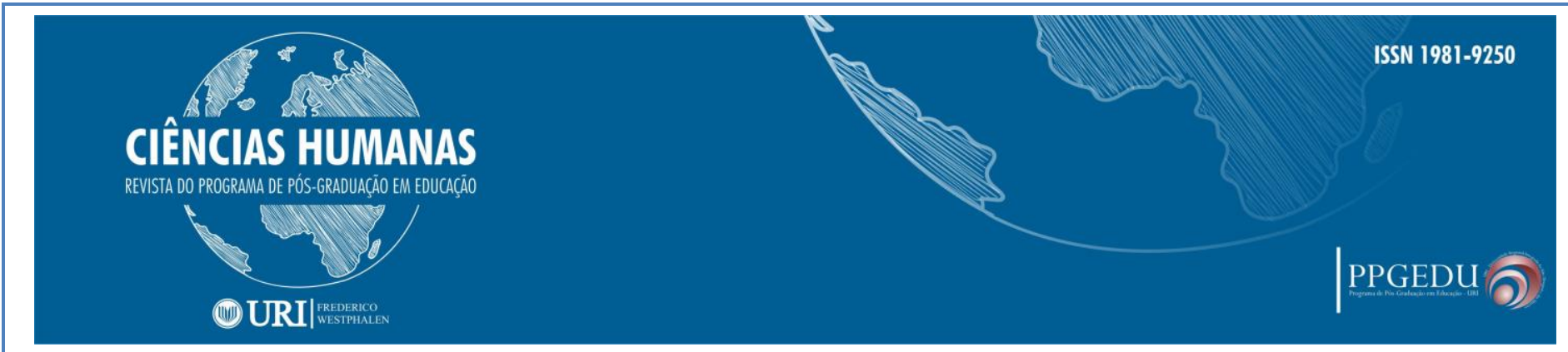

simples, quando se considera, por exemplo, a existência de perguntas retóricas ou pedagógicas, isto é, quando no fundo a relação entre saber e perguntar foi cindida.

Escreve Gadamer (2013, p. 47) "Não há método que ensine a perguntar, a ver o que se deve questionar. O exemplo de Sócrates ensina que o que importa é saber que não se sabe.”. A consciência da própria ignorância, para além de outras coisas, nos faz perceber a limitação da vida, da experiência e do saber livresco, pois sempre há algo que nos toca à uma pergunta genuína, no entanto, algumas vezes, preferimos ficar aquém de resolver uma limitação de saber e criar perguntas para as quais já temos alguma ideia de resposta. Ora, essas respostas estão no âmbito da opinião (doxa), não são respostas porque não são frutos de perguntas. São discursos que sem questionamento vamos agregando ao nosso repertório. Para perguntar é, portanto, necessário que se coloque em jogo as determinações e que se saiba que não se sabe.

Mas isso não está em nosso campo de liberdade, esse tipo de "ideia", que origina a pergunta, nos acomete. "É por isso que o próprio perguntar consiste mais num sofrer que num agir. A pergunta se impõe; chega um momento em que não podemos mais fugir dela, nem permanecer aferrados a opinião corrente". (GADAMER, 2013, p. 478).

Entretanto, quando na leitura de um texto nos ocorre a pergunta, a lógica se inverte, e o interpelado somos nós, leitores. O que está em suspenso agora não é a opinião do outro, mas a própria opinião que deve também entrar em diálogo.

\footnotetext{
A estreita relação que se mostra entre perguntar e compreender é a única que dá sua real dimensão à experiência hermenêutica. Aquele que quer compreender pode deixar em suspenso a verdade do que tem em mente. Ele pode ter retrocedido desde a intenção imediata da coisa à intenção de sentido como tal, e considerar esta não como verdadeira, mas simplesmente como algo com sentido, de maneira que a possibilidade de verdade fique em suspenso. (GADAMER, 2013, p. 489)
}

A suspensão da verdade, enquanto geradora de perguntas, não impede que o dito seja verdadeiro em si e que seja respeitado como tal, mas impede a aceitação pueril do que é dito. Tendo em vista que a minha possível verdade e a possível verdade do outro estão suspensas no processo dialético, o que se dá não é a defesa de opiniões, mas a busca pelo saber.

É no âmbito da experiência de encontro com o outro que nasce a pergunta, e diferente da hermenêutica metodológica, não podemos ficar às voltas com um termo, uma frase, enfim, um mal escrito, mas responder àquilo que se apresenta como questão. A esse encontro, que 


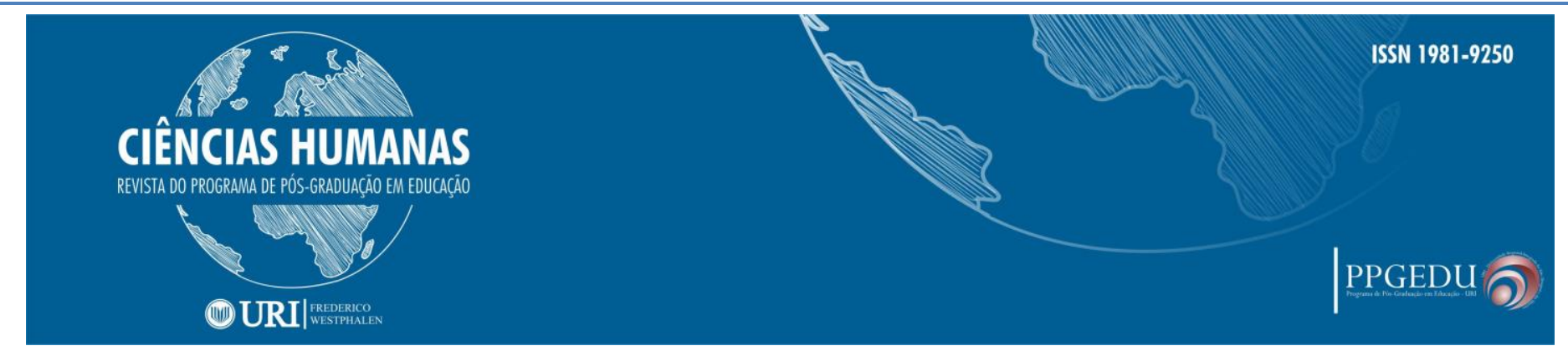

deixa colocada uma questão, chamamos experiência hermenêutica, seguimos aprofundando esse assunto.

\section{A Experiência Hermenêutica}

A experiência hermenêutica é a experiência da finitude humana frente ao outro, afirmamos isso tendo em vista algumas características centrais: a impossibilidade de repetição; a quebra da expectativa; a consideração da historicidade do outro e de si.

A repetição de uma experiência torna-se impossível a partir do momento em que consideramos a própria historicidade e finitude como condição, a experiência sempre significa a alteração de nosso próprio ser. Quando se faz uma experiência não é o outro que está jogado na experiência, é o eu que está em jogo, o eu que é finito e histórico, mas não é acabado.

\footnotetext{
Mas com isso o conceito de experiência em questão agora adquire um momento qualitativamente novo. Não se refere somente à experiência no sentido de que ela instrui sobre isto ou aquilo. Refere-se à experiência em seu todo. Esta é a experiência que cada um constantemente deve adquirir e a que ninguém pode se poupar. (GADAMER, 2013, p. 465)
}

Ora, dizer que não podemos nos poupar da experiência demonstra o caráter dolorido da mudança, que a quebra da expectativa impõe. Com isso chegamos ao discernimento, isto é, o conhecimento que libera o ser de amarras que o limitam em sua existência. Saber-se finito, esse é o discernimento que se adquire com uma experiência. Isso não significa que as coisas em que acreditamos perdem o sentido frente a finitude, mas que é possível encontrar, dentro de nossa condição histórica "possiblidade de futuro" para essas.

\footnotetext{
Saber que se é um ser finito repousa na consciência histórica, isto é, no reconhecimento de uma tradição, tendo em vista que "a tradição não é simplesmente um acontecer que aprendemos a conhecer e dominar pela experiência, mas é linguagem, isto é, fala por si mesma, como um tu" (GADAMER, 2011, p.467)
}

Estar atento a essa fala significa ser participante na tradição, quem quer compreender não submete a fala da tradição ao método, pelo contrário, é capaz de reconhecer sua validade e permitir que fale. Entretanto, não podemos confundir isso com aceitação e submissão, mas devemos considerar aí, na abertura para o que vem à fala, a possibilidade de ser 


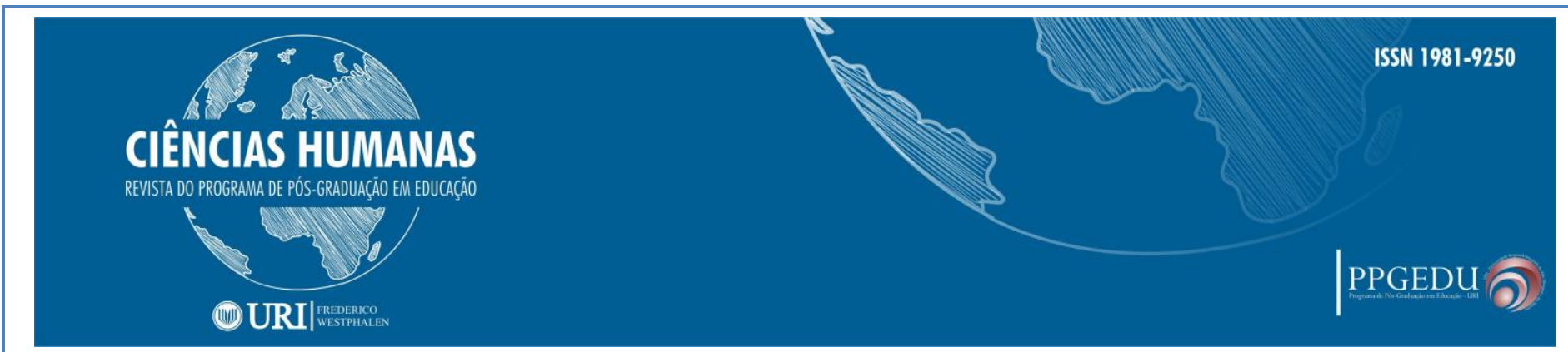

experienciado, isto é, de ser capaz de reconhecer que o outro pode ter uma visão mais acertada e mudar.

A partir da consideração dos itens precedentes, podemos considerar que, anterior a compreensão, é necessário conhecer a condição de seres existentes dentro de uma tradição, que nos determina em muitos aspectos, e perceber que só no querer saber sobre o que nos diz a tradição é que se pode compreender, e não submeter, o ser que se chamou para o diálogo. A linguagem é, para a hermenêutica filosófica, o modo de se mostrar, logo, quando nos dispomos a uma experiência, significa, colocar-nos abertamente para a linguagem. Compreendemos o outro porque compreendemos a linguagem, que não é do outro, mas o espaço de encontro com o outro.

Consideramos a questão pela verdade e chegamos à conclusão de que esta é uma experiência que se dá na esfera pré-política. Caso venha a participar da esfera política será metamorfoseada em discurso de opinião, podendo se apresentar como um saber que está no âmbito do preconceito e dos dogmas. A quebra da opinião se dá pela experiência, isto é, discernir o quão possível é que esse saber seja válido para a condição finita que possuímos, eis aí um processo metamórfico em que a opinião pode encontrar um horizonte de validade. Deve-se ressaltar que, apenas, quando colocado no aberto, enquanto pergunta é que se pode levar, por um processo dialético, um preconceito a apresentar seus fundamentos e seu impacto em nossa existência.

Nessa direção, considerando o objeto de nosso interesse neste estudo, ou seja, o discurso do MESP, estabelecemos um modo, não rígido, de recepcionar os textos, a saber:

a) que a quem decidiu aderir e encontrou sentido dentro da proposta do movimento, os textos podem ser tomados como verdade, o que invalida qualquer tentativa de emitir juízos de valor; b) que cada texto selecionado encerra em si um discurso de opinião, cujos fundamentos sem encontram em alguma tradição de pensamento, o que nos cabe é entrar em diálogo com essa tradição;

c) que sendo discursos de opinião estão no âmbito político, na esfera pública da sociedade, e o convencimento do público acerca da validade de suas proposições significa a aceitação de uma tradição de pensamento, que deverá determinar práticas dentro da sociedade. Esse fato 


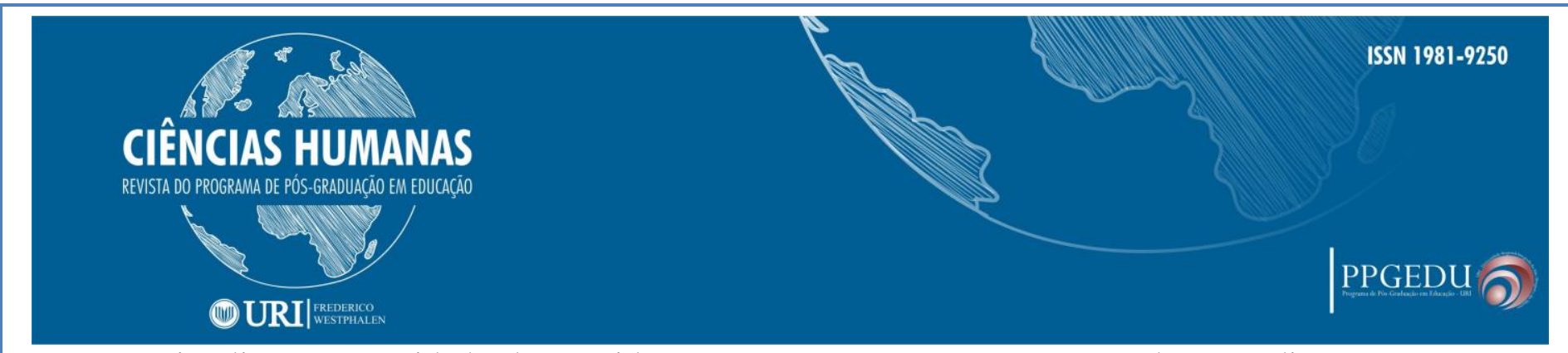

implica a necessidade de considerar, atentamente, os pressupostos dessa tradição, que não sabemos ainda qual é.

O que aparece em pauta na conclusão desse item, é a transparência necessária para que se possa dar ao estudo um tratamento ético adequado. O MESP não é um problema em nossa sociedade, ele é uma realidade que se estrutura dentro da sociedade, que dá condições para que tome forma e se consolide enquanto movimento válido. Se há uma preocupação em lhe dar um tratamento ético é porque sabemos o quão inconsistente é o terreno da opinião, ora, assim, só poderemos lançar alguma pergunta onde há a possibilidade de reposta consistente, a saber, na tradição.

A partir disso também definimos outro parâmetro, o de escolha dos materiais do site, e como estamos trabalhando, principalmente, com a sessão artigos analisaremos apenas aqueles elaborados por profissionais vinculados a instituição de ensino superior (IES), isto é, professores e pesquisadores. Ao fazer uma busca no site pelo termo "Paulo Freire", apenas quatro textos, dos quarenta e oito retornados, pertenciam à sessão artigos e atendiam ao pressuposto de serem redigidos por um professor ou pesquisador vinculado a IES. Nesse momento, olharemos para a abordagem de um texto, cujo autor possui representatividade considerável, já que onze textos publicizados no site do MESP carregam seu nome, enquanto outros autores possuem no máximo dois textos divulgados.

\section{POR QUE PAULO FREIRE?}

Paulo Freire é um dos pensadores mais comentados nos artigos do site do MESP. Seu legado permeia as universidades, programas de formação de professores e escola básica, no Brasil e no exterior. Mas atacando Paulo Freire, os autores atacam uma tradição que influenciou e que sofre influência do pensador. Apesar de Freire ter pautado seu pensamento em um diálogo entre algumas vertentes teóricas, como a fenomenologia, o MESP centra foco nas aproximações de Freire com o marxismo.

O artigo "Paulo Freire e a 'educação bancária' ideologizada”, redigido por Luiz Lopes Diniz Filho, se desenrola como uma crítica à reportagem publicada no periódico Gazeta do Povo e apresenta, utilizando uma situação hipotética, a proposta de Paulo Freire como 


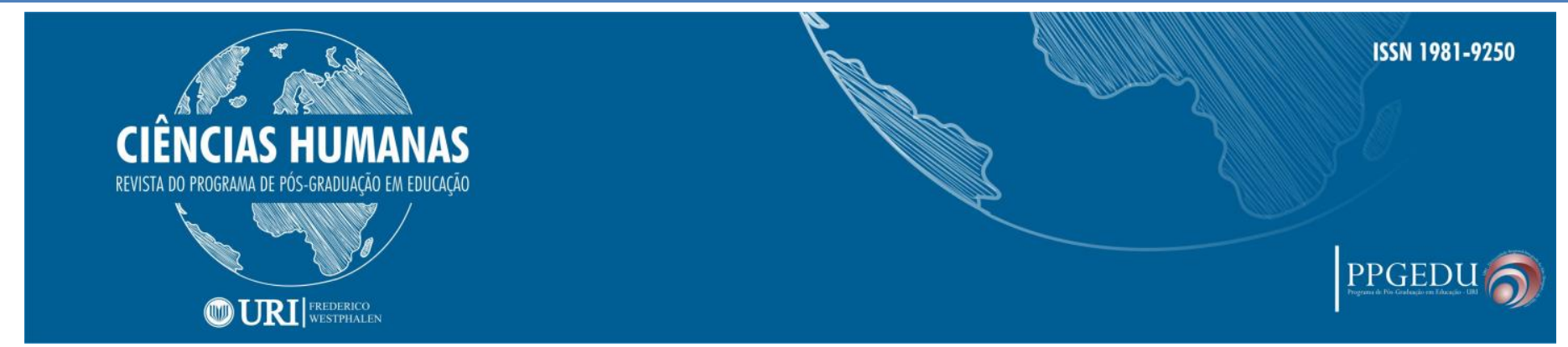

[...] um método que consiste em transmitir ao aluno verdades prontas, tal como na dita "educação bancária", mas disfarçado por um processo dialógico manipulado pelo professor, que sonega ao aluno o conhecimento de explicações alternativas e mais sofisticadas [...] (FILHO, 2018)

O que temos aqui é um problema na aplicação da teoria sobre "educação bancária" e de entendimento sobre como procede, segundo os parâmetros do pensamento freiriano, adaptados para o contexto de sala de aula, o professor que recebe a inquietação de um estudante.

Sobre o que seja a educação bancária, afirma Freire em Pedagogia do Oprimido:

Na visão "bancária" da educação, o "saber" é uma doação dos que se julgam sábios aos que julgam nada saber. Doação que se funda numa das manifestações instrumentais da ideologia da opressão - a absolutização da ignorância, que constitui o que chamamos de alienação da ignorância, segundo a qual essa se encontra sempre no outro. (FREIRE, 1987, p. 58)

Logo, apenas na educação bancária é possível "transmitir verdades prontas" e "sonegar conhecimento", ações que passam ao largo da proposta de Freire. Pois, sob o pensamento de Paulo Freire, o professor não tem o conhecimento, como coisa que pode ser doada ou sonegada. Nem mesmo, necessita a presença de um professor para que o humano estabeleça uma relação de conhecimento:

O que não percebem os que executam a educação "bancária", deliberadamente ou não [...], é que nos próprios "depósitos" se encontram as contradições, apenas revestidas por uma exterioridade que as oculta. E que, cedo ou tarde, os próprios "depósitos" podem provocar um confronto com a realidade em devenir e despertar os educandos, até então passivos, contra a sua "domesticação". (FREIRE, 1987, p. 61)

Isto é, o processo dialético, que ocorre entre a tese apresentada ao estudante e a realidade em que ele vive, não depende de intervenção, pode vir a acontecer com o próprio esforço do estudante em compreender como uma teoria se apresenta no mundo ou mesmo como um processo de compreensão do próprio meio.

Ilustramos nas palavras de Vinicius de Morais:

$[\ldots]$

Â mesa, ao cortar o pão / O operário foi tomado / De uma súbita emoção / Ao constatar assombrado / Que tudo naquela mesa / - Garrafa, prato, facão - / Era ele quem os fazia / Ele, um humilde operário, / Um operário em construção.

$[\ldots]$ 


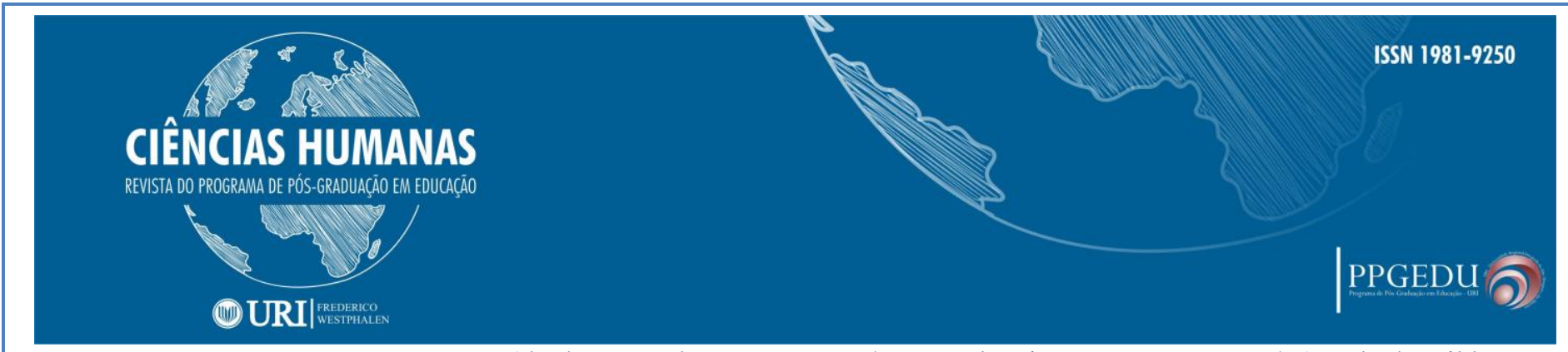

Ah, homens de pensamento / Não sabereis nunca o quanto / Aquele humilde operário / Soube naquele momento! / Naquela casa vazia / Que ele mesmo levantara / Um mundo novo nascia / De que sequer suspeitava.

O operário emocionado / Olhou sua própria mão / Sua rude mão de operário / De operário em construção / E olhando bem para ela / Teve um segundo a impressão / De que não havia no mundo / Coisa que fosse mais bela.

Foi dentro da compreensão / Desse instante solitário / Que, tal sua construção / Cresceu também o operário.

$[\ldots]$

E um fato novo se viu / Que a todos admirava: / O que o operário dizia / Outro operário escutava.

E foi assim que o operário / Do edifício em construção / Que sempre dizia sim / Começou a dizer não.

E aprendeu a notar coisas /A que não dava atenção: / Notou que sua marmita / Era o prato do patrão / Que sua cerveja preta / Era o uísque do patrão / Que seu macacão de zuarte / Era o terno do patrão

[...] (MORAES, 2018)

Enquanto a prática de um professor que pretende doutrinar seus alunos, usando Paulo

Freire, fica o alerta sobre a denúncia da educação bancária:

\begin{abstract}
A educação como prática da dominação, que vem sendo objeto desta crítica, mantendo a ingenuidade dos educandos, o que pretende, em seu marco ideológico (nem sempre percebido por muitos dos que a realizam), é indoutriná-los no sentido de sua acomodação ao mundo da opressão. Ao denunciá-la, não esperamos que as elites dominadoras renunciem à sua prática. Seria demasiado ingênuo esperá-lo. Nosso objetivo é chamar a atenção dos verdadeiros humanistas para o fato de que eles não podem, na busca da libertação, servir-se da concepção bancária, sob pena de se contradizerem em sua busca. Assim como também não pode esta concepção tornar-se legado da sociedade opressora à sociedade revolucionária. A sociedade revolucionária que mantenha a prática da educação "bancária" ou se equivocou nesta manutenção, ou se deixou "morder" pela desconfiança e pela descrença nos homens. Em qualquer das hipóteses, estará ameaçada pelo espectro da reação. (FREIRE, 1987, p. 66)
\end{abstract}

Logo, o que poderia afirmar o autor do referido artigo, é que existe a possibilidade, como bem previu Paulo Freire, de confusão sobre o que seja uma consciência liberta e, na busca por essa, cair o professor em educação bancária travestida de educação libertadora. Ora, isso apenas legitima a defesa do genuíno pensamento freiriano, e jamais do ataque.

Se alguma limitação na teoria freiriana é observada - assim como foi observada em Platão, Agostinho, Descartes, Kant, Hegel - não cabe a nós, sujeitos de outro tempo, jogar na lata do lixo suas ideias, mas superar o que é limitador e seguir com as contribuições que nos tiram da menoridade. Caso não fosse essa a relação com os conhecimentos já produzidos, uma relação de respeito com o dito alheio, não andariam as editoras arrecadando com os

\begin{tabular}{l|l} 
Recebido em: 26/04/2019 & Aceito em: 30/04/2019
\end{tabular}




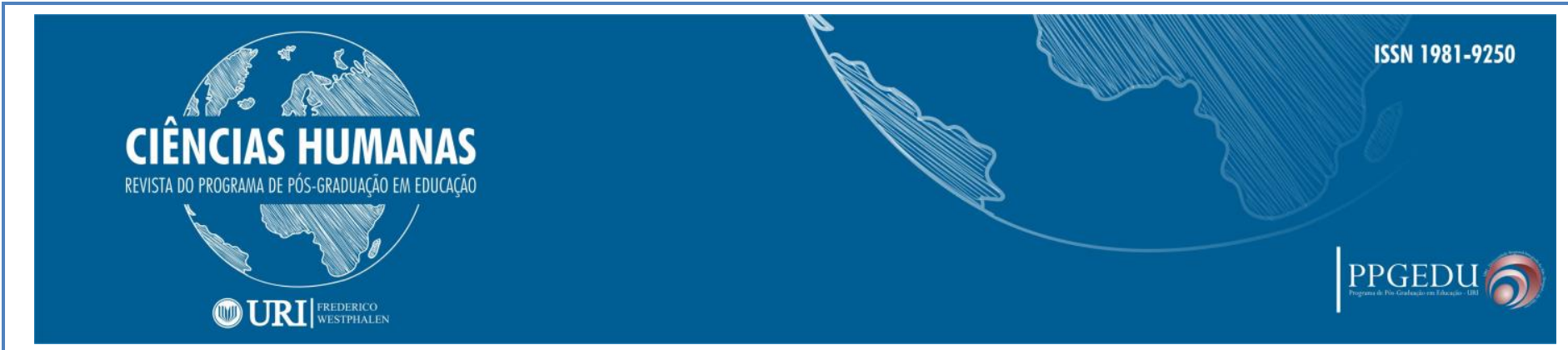

pensadores supracitados, cujas teorias ainda colaboram e balizam para pensar nosso tempo. Ora, se o pensamento de Paulo Freire vem atravessando décadas não se faz por influência de jogada político-ideológica, mas sim porque se fez clássico, isto é, "não é algo que requeira a superação da distância histórica; pois ele mesmo realiza essa superação em constante mediação. Nesse sentido, o que é clássico é, sem dúvida, "intemporal”, mas essa intemporalidade é um modo de ser histórico”. (GADAMER, 2013, p.384)

Logo, o pensamento em questão aqui tem algo a nos dizer, e essa contradição que vem apresentando o MESP é a chamada para que nos apropriemos desse clássico do pensamento pedagógico, para, com conhecimento de causa, apontar o que é legitimo em termos de limites e avanços. Não permitindo que críticas vazias, baseadas em situações hipotéticas, esfarelem um dos raros pensamentos criados a partir do genuíno diálogo entre teoria e prática formativa.

\section{CONSIDERAÇÕES}

Como observamos, o encontro entre os humanos requereu uma organização que viemos a chamar, na modernidade, de Estado, que se mantém pela existência dos cidadãos formados por várias instâncias, mas principalmente na instituição escolar. No entanto, com o advento do social, o Estado passa a ser fortemente influenciado por dimensões da vida particular, principalmente a economia, que se torna fator preponderante até mesmo para pensar o acesso aos que eram reconhecidamente direitos básicos do cidadão: segurança, saúde e educação.

O econômico se mostra na educação a partir de políticas que definem o próprio conceito de educação, os conteúdos, a metodologia, enfim, a configuração escolar em sua totalidade de funcionamento. Essas definições, quando postas pelo econômico, se fazem por parcerias entre setor público e privado, e mesmo na manutenção próprio setor público visando a esfera econômica. É habito, no entanto que as justificativas se refiram a qualidade da educação para as medidas adotadas, raras vezes encontramos outras justificativas.

O Movimento Escola Sem Partido não utiliza, em seus artigos, a qualidade da educação como fator estanque para justificar sua existência, mas a "contaminação políticoideológica" presente nas aulas, principalmente das ciências humanas. Suas críticas são 


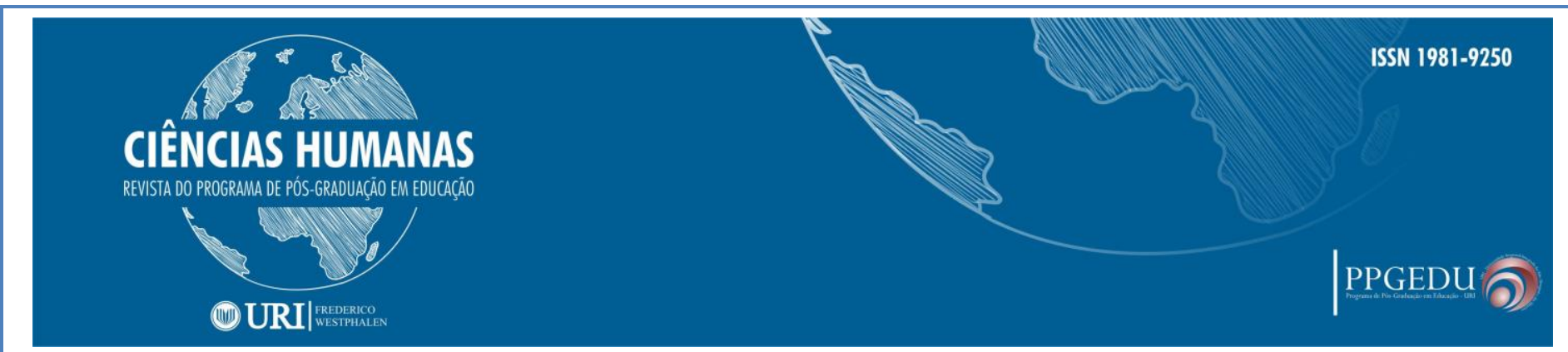

dirigidas as universidades e professores de educação básica, que utilizam de referencial teórico de vertente crítica. Seus ditos são oriundos e corroborados no âmbito da opinião pública.

A partir disso nos propomos a dialogar, para esta proposta, com um trabalho que versa sobre a teoria de Paulo Freire. Observamos que a própria teoria em jogo não admite a unilateralidade de pensamento, porque tem como causa final o pensar autônomo. Logo, se a escola vem se desligando de sua função de promover o conhecimento formal, isso não se faz com a compreensão da obra de Paulo Freire, mas com o uso raso de seus pensamentos.

Percebemos, no entanto, que os discursos contra as teorias críticas ganham terreno quando não há a vontade de conhecer, mas apenas de encontrar suporte para levar a feito uma proposta, como o MESP, que vem se desvelando como mais uma tentativa de regulação, responsabilização e desvalorização da profissão docente.

\section{REFERÊNCIAS}

AFONSO, Almerindo Janela. Protagonismos instáveis dos princípios de regulação e interfaces público/privado em educação. Educação e Sociedade, vol.31, n.113, pp.11371156, 2010.

ARENDT, Hannah. A Condição Humana. Rio de Janeiro: Forense Universitária, 2010.

ARENDT, Hannah. Entre o Passado e o Futuro. São Paulo: Perspectiva, 2009.

BARROSO, João. Políticas Educativas e Organização Escolar. Lisboa: Universidade Aberta, 2005.

FILHO, Luiz Lopes Diniz. Paulo Freire e a 'Educação Bancária' Ideologizada. Disponível em <http://www.escolasempartido.org/artigos-top/382-paulo-freire-e-a-educacao-bancariaideologizada $>$. Acesso em: 16 de abr. 2018.

FREIRE, Paulo. Pedagogia do Oprimido. Rio de Janeiro: Paz e Terra. 1987.

GADAMER, Hans-Geog. Verdade e Método I: traços fundamentais de uma hermenêutica filosófica. Petrópolis: Vozes, 2013.

GADAMER, Hans-Geog. Verdade e método II: Complementos e índice. Petrópolis: Vozes, 2011. 


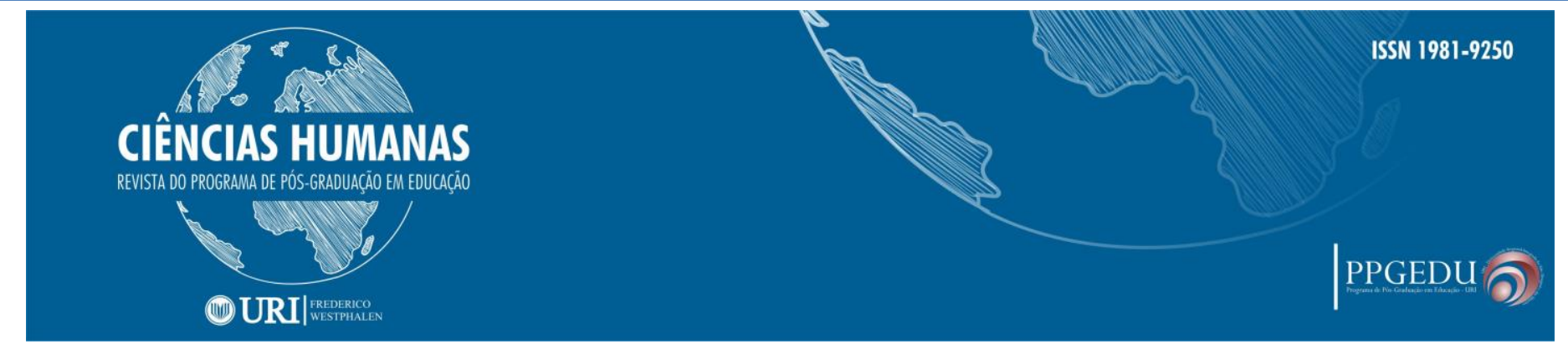

GALEANO, Eduardo. De pernas pro ar: a escola do mundo avesso. Porto Alegre: L\&PM Editores. 2009.

GOERGEN, Pedro. A educação como direito de cidadania e responsabilidade do Estado. Educação e Sociedade, vol.34, n.124, pp.723-742, 2013.

MORES, Vinicius de. Operário em Construção. Disponível em:

<http://www.viniciusdemoraes.com.br/pt-br/poesia/poesias-avulsas/o-operario-emconstrucao>. Acesso em: 26 de abr. 2018. 